\title{
Analysis of Drug Content and Weight Uniformity for Half-Tablets of 6 Commonly Split Medications
}

\author{
Shaynan W. Hill, PharmD; Andrew S. Varker, PharmD; Kelly Karlage, BS; and Paul B. Myrdal, PhD
}

\begin{abstract}
BACKGROUND: Cost savings can be achieved with the practice of tablet splitting. Previous research has shown weight nonuniformity within tablet halves. However, limited research to date has found that the potential dose inaccuracy resulting from splitting tablets does not significantly affect clinical outcomes.
\end{abstract}

OBJECTIVE: To determine the drug content and weight in split half-tablets of 6 commonly split medications using drug assay analysis.

METHODS: This study was performed by 2 fourth-year pharmacy students using 30 randomly selected tablets of each of the following 6 medications: warfarin sodium 5 milligrams (mg), simvastatin $80 \mathrm{mg}$, metoprolol succinate $200 \mathrm{mg}$, metoprolol tartrate $25 \mathrm{mg}$, citalopram $40 \mathrm{mg}$, and lisinopril $40 \mathrm{mg}$. A randomly selected half of the tablets were split by a single pharmacy student using a tablet cutter, and the remaining tablets were kept whole. Drug content was analyzed for 15 whole tablets and 30 half-tablets for each of the 6 drugs using high performance liquid chromatography, an analytical tool used to identify and quantify substances in solution. Drug content uniformity was assessed by comparing drug content within halftablets with one-half of the drug content mean found for all whole tablets in the sample. Weight uniformity was assessed by comparing half-tablet weights, as determined by a Mettler analytical balance, with one-half of the mean weight for whole tablets in the sample. The percentages by which each whole tablet's or half-tablet's drug content and weight differed from sample mean values were compared with proxy United States Pharmacopeia (USP) specification ranges for drug content (95\%-105\% for warfarin sodium and $90 \%-110 \%$ for the other 5 drugs). Additionally, these outcomes were compared for nonscored versus scored tablets. The percent relative standard deviation (\%RSD, ratio of the standard deviation to the mean), a commonly used measure of the repeatability and precision of assays used to analyze drug content, was also calculated in order to determine whether the drugs met proxy USP specification for \%RSD (less than $6 \%$ for all drugs studied).

RESULTS: A total of 43 of 180 half-tablets (23.9\%) differed from sample mean values by a percentage that fell outside of proxy USP specification for drug content; warfarin sodium (11 of 30 half-tablets, $36.7 \%$ ), simvastatin ( 3 of 30 half-tablets, $10.0 \%$ ) metoprolol succinate ( 10 of 30 half-tablets, $33.3 \%$ ), metoprolol tartrate (4 of 30 half-tablets, $13.3 \%$ ), citalopram (5 of 30 half-tablets, $16.7 \%$ ), and lisinopril (10 of 30 half-tablets, $33.3 \%$ ). Half-tablets outside of proxy USP specification for weight included warfarin sodium (10 of 30 half-tablets, $33.3 \%$ ), metoprolol succinate (6 of 30 half-tablets, $20 \%$ ), and lisinopril (7 of 30 half-tablets, $23.3 \%$ ). The \%RSDs for drug content and weight fell outside of the proxy USP specification for $\%$ RSD for metoprolol succinate (drug content $=8.98 \%$, weight $=7.70 \%$ ) and lisinopril (drug content $=10.41 \%$, weight $=8.13 \%$ ). Mean percent weight loss after splitting was less than $1 \%$ for all drugs except lisinopril, which had an average weight loss of $1.25 \%$. The total numbers of scored (nonscored) tablet halves that fell outside of proxy USP specification were 20 (23) for drug content and 10 (13) for weight. When measuring drug content, the numbers of out-of-range half-tablets for scored (nonscored) drugs were $36(44)$ at $95 \%-105 \%, 9(23)$ at $90 \%-110 \%, 0(10)$ at $85 \%-115 \%$, and $0(1)$ at $75 \%-125 \%$. When measuring weight, the numbers of out-of-range halftablets for scored (nonscored) drugs were 28 (38) at 95\%-105\%, 0 (14) at $90 \%-110 \%, 0(3)$ at $85 \%-115 \%$, and $0(0)$ at $75 \%-125 \%$.

Note: This article is the subject of a commentary that appears on pages 272-274 of this issue.
CONCLUSION: Dose variation exceeded a proxy USP specification for more than one-third of sampled half-tablets of warfarin sodium, metoprolol succinate, and lisinopril and appeared to be greater for nonscored tablets as compared with scored tablets. Drug content variation in half-tablets appeared to be attributable primarily to weight variation occurring when tablets powder or fragment during the splitting process. Therefore, equal daily doses will be determined by the ability of patients to split tablets perfectly in half.

J Manag Care Pharm. 2009;15(3):253-61

Copyright $\odot$ 2009, Academy of Managed Care Pharmacy. All rights reserved.

\section{What is already known about this subject}

- Manufacturers of FDA-approved medications are required to adhere to the United States Pharmacopeia (USP) established ranges for drug content of whole tablets. The USP has created guidelines to compare drug content for whole tablets; however, no guidelines have been established to assess the drug content of half-tablets.

- Teng et al. (2002) found that only 3 of 11 medications passed an adapted USP uniformity test when half-tablet drug content uniformity was estimated from half-tablet weight after splitting of tablets by hand or razor blade.

- To date, 4 published studies have shown that the potential inaccuracy of dose resulting from splitting tablets does not significantly affect clinical and humanistic outcomes.

\section{What this study adds}

- This is the first study to determine drug content uniformity within half-tablets using drug assay; target drug content was defined as one-half of the per-tablet mean drug content for all whole tablets in a sample of 15 whole tablets each of 6 commonly split medications.

- More than $30 \%$ of measured half-tablets ( $n=30$ each drug) of warfarin sodium, metoprolol succinate, and lisinopril differed from the target drug content by a percentage that fell outside of the proxy USP specification (95\%-105\% for warfarin sodium and $90 \%-110 \%$ for the other 5 drugs). For all other medications studied (simvastatin, metoprolol tartrate, and citalopram), 10\%$17 \%$ of half-tablets fell outside of proxy USP specification for drug content.

- Only 5 of 180 (2.8\%) half-tablets in a weight-adjusted analysis, as compared with 43 of 180 (23.9\%) half-tablets in an analysis that was not weight-adjusted, fell outside of the proxy USP specification for drug content. Thus, drug content variation in half-tablets appears to be attributable primarily to weight variation occurring when tablets powder or fragment during the splitting process. 
$\mathrm{T}$ ablet splitting has become increasingly common, especially within the geriatric and psychiatric communities, as a means of reducing medication dose and/or cost. Physicians frequently write prescriptions for half-tablets in order to achieve doses less than the smallest available manufactured strength. Prescribers also write for half- and quarter-tablet doses of higher-strength tablets in order to reduce costs because parity pricing (the use of flat rates for medications independent of dose strength) is common. Cohen and Cohen (2000) showed that an annual savings of $\$ 1.45$ billion could be achieved when tablet splitting was performed for 12 specific psychotropic medications, while annual savings of $\$ 725$ million and $\$ 325$ million could be achieved from splitting one-half and one-fourth of prescriptions written, respectively. ${ }^{1}$ Cohen and Cohen later (2002) estimated potential cost savings of $\$ 1.7$ billion nationally if tablet splitting was performed for 7 antidepressant medications. ${ }^{2}$ Miller et al. (2007) found that tablet splitting contributed $\$ 342,239$ (about $\$ 1.30$ per member per month [PMPM]) or $17.3 \%$ of total annualized savings of $\$ 1,983,153$ attributed to 4 managed care interventions that included (a) moving certain brand name drugs in 6 drug classes to nonpreferred status, (b) removing low-sedating antihistamines from the formulary, (c) limiting the quantity supplied for sedative sleep aids, and (d) tablet splitting for 9 brand name drugs (6 antidepressants and 3 statins). ${ }^{3}$ Stafford and Radley (2002) estimated that tablet splitting for 11 drugs was infrequent, accounting for annual savings of only \$0.03 PMPM compared with potential savings of $\$ 1.14$ PMPM. $^{4}$

Although cost savings may be accomplished, problems may arise with tablet splitting such as poor cognitive function or memory, the inability of patients to effectively split tablets, and the fear of inaccurate dose. The "Uniformity of Dosage Units" section in the U.S. Pharmacopeia (USP) manual states that each unit within a single lot of a given medication should have drug substance content that is within a narrow range around the labeled claim. ${ }^{5}$ Several studies have looked at weight variation of split tablets as a means of estimating drug content uniformity. Teng et al. (2002) evaluated the weight uniformity of 11 commonly split medications through an analysis of half-tablet weights, using a uniformity test adapted from the USP specifications. ${ }^{6}$ Eight medications were split using a single-edged razor blade, and 3 were split by hand (i.e., using only tensile strength of the fingers or hands). Results revealed that only 3 of 11 medications passed their adapted USP specifications, and there were no obvious tablet features (e.g., scoring) that determined whether a tablet would pass or fail the uniformity test. This study also found that tablets split by hand showed less uniformity than did tablets split using a razor blade, even though splitting tablets by hand produced cleaner splits with less tablet crumbling.

A similar study performed by Polli et al. assessed content uniformity through the analysis of half-tablet weights using the same adapted USP methods as used by Teng et al..$^{7}$ In contrast to the results found by Teng et al., this study, performed at a
Department of Veterans Affairs (VA) center, found that 8 out of 12 medications split with a tablet-splitting device passed the adapted uniformity test. ${ }^{7}$ Another study analyzed the drug weight uniformity of cyclobenzaprine tablets split in half using either a tablet splitter or a kitchen knife. ${ }^{8}$ The results showed that both methods resulted in a wide variation in fragment weight between $49.9 \%$ to $149.5 \%$ of the theoretical weight (defined as one-half of the mean weight of the intact tablet) using a kitchen knife and $69.4 \%$ to $130.2 \%$ using the tablet splitter. Thus, both methods failed the quality standards for dosage uniformity of manufactured drugs as outlined by Teng et al. ${ }^{8}$ Rosenberg et al. (2002) evaluated content uniformity of discontinued pharmacist-dispensed split-tablet samples taken from 4 long-term care facilities using a total of 560 fragments. ${ }^{9}$ These authors found that 2 of 22 medications had significantly different fragment weights as compared with the theoretical weight of the half-tablets. The researchers also found that 30 of the 560 fragments deviated by more than $15 \%$ of the sample mean fragment weight, and 32 of the 560 fragments deviated by more than $15 \%$ of the theoretical weight. Lastly, 15 of the 22 medications were found to have relative standard deviations for weight expressed as a percentage (\%RSDs) in excess of $6 \%$, the upper limit of the USP specification. ${ }^{9}$

Although studies of weight differences among split tablets have been performed, the more important analysis of drug content has yet to be explored. Studies to date have assessed drug content uniformity only as variation in half-tablet weights. These studies adapted the USP manual section entitled "Uniformity of Dosage Units" - criteria developed to ensure that actual drug content is equivalent to manufacturer-labeled drug content-and indirectly measured half-tablet drug content by measuring halftablet weight. ${ }^{5}$ Although USP guidelines enforce strict adherence to drug content per dosage unit for whole tablets, guidelines for the drug content of split tablets have yet to be established.

In the present study, we defined the target drug content and weight of a half-tablet as equal to one-half of the mean drug content and weight, respectively, for all whole tablets in a sample of 6 commonly split medications. To assess the acceptability of variation in the half-tablets, defined as the percentage by which each individual whole tablet and half-tablet differed from the sample mean values, we adapted USP specifications for drug content and weight of whole tablets (proxy USP specification). We hypothesized that the drug content and weight of half-tablets would deviate from these proxy specifications.

\section{Methods}

Six drugs were studied: warfarin sodium 5 milligrams (mg), simvastatin $80 \mathrm{mg}$, metoprolol succinate $200 \mathrm{mg}$, metoprolol tartrate $25 \mathrm{mg}$, citalopram $40 \mathrm{mg}$, and lisinopril $40 \mathrm{mg}$ (Table 1). These drugs were chosen because they were observed to be commonly split within a single VA health care network. A total of 30 whole tablets were randomly selected from each medication lot for each of the 6 drugs. All 30 whole tablets were weighed using a Mettler 


\section{TABLE 1) Descriptions of Drugs Studied}

\begin{tabular}{|c|c|c|c|c|c|}
\hline Drug & Manufacturer & $\begin{array}{c}\text { Lot Number } \\
\text { Expiration (Date) }\end{array}$ & Tablet Description & Scored & Observations $^{a}$ \\
\hline $\begin{array}{l}\text { Warfarin sodium } \\
5 \mathrm{mg}\end{array}$ & $\begin{array}{l}\text { Taro Pharmaceuticals } \\
\text { U.S.A. Inc., Hawthorn, NY }\end{array}$ & $\begin{array}{c}077079 \\
(02 / 2010)\end{array}$ & $\begin{array}{l}\text { Peach, non-coated, } \\
\text { oblong tablet }\end{array}$ & Yes & $\begin{array}{l}\text { Moderate powdering with tablet splitter, } \\
\text { fractured at score }\end{array}$ \\
\hline $\begin{array}{l}\text { Simvastatin } \\
80 \mathrm{mg}\end{array}$ & $\begin{array}{l}\text { Dr. Reddys Laboratories } \\
\text { Limited, Bachepalli, India }\end{array}$ & $\begin{array}{c}\text { C71045 } \\
(03 / 2009)\end{array}$ & $\begin{array}{l}\text { Mauve, film-coated, } \\
\text { oval tablet }\end{array}$ & No & $\begin{array}{l}\text { Minimal powdering with tablet splitter, } \\
\text { fractured into equal halves }\end{array}$ \\
\hline $\begin{array}{l}\text { Metoprolol succinate } \\
200 \mathrm{mg}\end{array}$ & $\begin{array}{l}\text { AstraZeneca LP, } \\
\text { Wilmington, DE }\end{array}$ & $\begin{array}{c}\text { ML0189 } \\
(07 / 2009)\end{array}$ & $\begin{array}{l}\text { White, film-coated, } \\
\text { oval tablet }\end{array}$ & No & $\begin{array}{l}\text { Moderate powdering with tablet splitter, } \\
\text { fractured into equal halves }\end{array}$ \\
\hline $\begin{array}{l}\text { Metoprolol tartrate } \\
25 \mathrm{mg}\end{array}$ & $\begin{array}{l}\text { Mylan Pharmaceuticals } \\
\text { Inc., Morgantown, WV }\end{array}$ & $\begin{array}{c}\text { 7M748 } \\
(03 / 2009)\end{array}$ & $\begin{array}{l}\text { White, non-coated, } \\
\text { circular tablet }\end{array}$ & Yes & $\begin{array}{l}\text { Minimal powdering with tablet splitter, } \\
\text { fractured at score }\end{array}$ \\
\hline $\begin{array}{l}\text { Citalopram } \\
40 \mathrm{mg}\end{array}$ & $\begin{array}{l}\text { Sandoz Inc., } \\
\text { Princeton, NJ }\end{array}$ & $\begin{array}{l}\text { CT4007008 } \\
(02 / 2009)\end{array}$ & $\begin{array}{l}\text { White, non-coated, } \\
\text { oblong tablet }\end{array}$ & Yes & $\begin{array}{l}\text { Minimal powdering with tablet splitter, } \\
\text { fractured at score }\end{array}$ \\
\hline $\begin{array}{l}\text { Lisinopril } \\
40 \mathrm{mg}\end{array}$ & $\begin{array}{l}\text { Sandoz Inc., } \\
\text { Princeton, NJ }\end{array}$ & $\begin{array}{l}\text { MK070711 } \\
(06 / 2010)\end{array}$ & $\begin{array}{l}\text { Yellow, non-coated, } \\
\text { oval tablet }\end{array}$ & No & $\begin{array}{l}\text { Significant powdering with tablet splitter, } \\
\text { fractured into equal halves }\end{array}$ \\
\hline
\end{tabular}

Toledo AG204 (Mettler Toledo, Inc., Columbus, Ohio) analytical balance that is accurate to $0.1 \mathrm{mg}$. Fifteen of the 30 randomly selected tablets were split in half by a single pharmacy student (SH), using a Locking Tablet Cutter (Apothecary Products, Inc.), and weighed with the Mettler Toledo analytical balance.

The 15 whole tablets and 30 half-tablets for each of the 6 drugs were then dissolved separately using a combination of manual agitation and sonication techniques in an appropriate diluent adapted from respective USP official monographs. All tablets were assayed in accordance with USP methodology for determining content uniformity for whole tablets. Assay parameters for each drug were taken directly from USP monographs; ${ }^{5}$ customary changes were made to allow for column optimization (Appendix). ${ }^{5}$ After the tablets were completely dissolved, samples of each solution were assayed for drug concentration via a Waters Alliance High Pressure Chromatography system, consisting of a 2695 Separations Module coupled with a 2487 Dual Wavelength ultraviolet (UV) detector (Waters Corporation, Milford, MA). A standard curve was created for each drug, using pure drug powder (obtained from LKT Laboratories, St. Paul, MN, or SigmaAldrich, St. Louis, MO) diluted to 5 known concentrations. These standard curves were established to verify accurate analysis of the drug, as opposed to any inactive tablet constituents, and to quantify drug content by calculating concentration from area under the curve data obtained through high performance liquid chromatography (HPLC) analysis of whole- and half-tablet samples.

The following parameters were assessed for each of the 6 medications (Table 2):

1. Measured drug content:

a. Each whole tablet's drug content $(n=15)$ was compared with the target drug content for whole tablets, defined as the mean measured drug content for all whole tablets in the sample.

b. Each half-tablet's drug content $(n=30)$ was compared with the target drug content for half-tablets, defined as one-half of the mean measured drug content for all whole tablets in the sample.

2. Weight-adjusted target drug content: To account for tablet powdering/fragmenting and the inability to split tablets into perfectly equal halves, each half-tablet's target drug content $(n=30)$ was adjusted for the weight of the fragment. The adjustment formula assumed that within a single half-tablet of known weight, the half-tablet's proportion of the whole-tablet drug content should equal the half-tablet's proportion of the whole-tablet weight (e.g., if a half-tablet was $51 \%$ of the wholetablet weight, it should equal $51 \%$ of the whole-tablet target drug content).

3. Measured weight:

a. Each whole tablet's weight $(n=15)$ was compared with the target weight for whole tablets, defined as the mean measured weight mean for all whole tablets in the sample.

b. Each half-tablet weight $(n=30)$ was compared with onehalf of the target weight for whole tablets.

4. For each tablet, the percentage weight loss due to fragmenting and/or powdering was calculated as ([measured weight of whole tablet - measured weight of both half-tablets] / measured weight of whole tablet) x 100 .

5. Nonscored drug tablets ( $\mathrm{n}=90$; simvastatin, metoprolol succinate, and lisinopril) were compared with scored drug tablets ( $\mathrm{n}=90$; warfarin sodium, citalopram, and metoprolol tartrate) on 2 outcome measures, half-tablet drug content and halftablet weight

To assess the amount and acceptability of variations in drug content and weight, several measures were calculated. The measured drug content expressed as a percent of target drug content was calculated for both whole and half-tablets using the following equation: ([target drug content - measured drug content] / target drug content) $\mathrm{x}$ 100. Individual values for whole tablets should 


\section{TABLE 2 Definitions of Terms}

\begin{tabular}{|c|c|}
\hline United States Pharmacopeia (USP) & $\begin{array}{l}\text { A publication that contains legally recognized standards of identity, strength, quality, purity, packaging, and labeling } \\
\text { for drug substances; dosage forms, and other therapeutic products, including nutritionals and dietary supplements. }\end{array}$ \\
\hline Percent (\%) RSD & $\begin{array}{l}\text { Ratio of the standard deviation to the mean. } \\
\frac{\text { standard deviation for measured variable } \times 100}{\text { measured variable mean }}\end{array}$ \\
\hline 5- point standard curve & $\begin{array}{l}\text { A curve consisting of } 5 \text { known concentrations of the drug created using pure drug-used to determine that the } \\
\text { drug was isolated by HPLC as opposed to other tablet constituents. }\end{array}$ \\
\hline $\begin{array}{l}\text { High Performance (Pressure) Liquid } \\
\text { Chromatography (HPLC) }\end{array}$ & A form of liquid chromatography used to separate compounds that are dissolved in solution. \\
\hline Measured drug content & The amount of drug (mg) determined to be within the whole or half-tablet analyzed using HPLC. \\
\hline Measured weight & The weight (mg) of the whole or half-tablet as measured using a Mettler analytical balance. \\
\hline $\begin{array}{l}\text { Target drug content for individual } \\
\text { tablet or half-tablet (measured drug } \\
\text { content mean per tablet for sample) }\end{array}$ & $\begin{array}{l}\text { Whole tablets: } \frac{\sum \text { drug content for whole tablets }}{\text { number of whole tablets }} \\
\text { Half-tablets: } \frac{\sum \text { drug content for half-tablets }}{\text { number of half-tablets }}\end{array}$ \\
\hline $\begin{array}{l}\text { Target weight for individual tablet or } \\
\text { half-tablet (measured weight mean } \\
\text { per tablet for sample) }\end{array}$ & $\begin{array}{l}\text { Whole tablets: } \frac{\sum \text { weight for whole tablets }}{\text { number of whole tablets }} \\
\text { Half-tablets: } \frac{\sum \text { weight for half-tablets }}{\text { number of half-tablets }}\end{array}$ \\
\hline Weight-adjusted target drug content & $\begin{array}{l}\text { The amount expected to be found within a single half-tablet of known weight, assuming that the half-tablet's } \\
\text { proportion of whole tablet drug content equals the half-tablet's proportion of whole tablet weight. } \\
\text { measured half-tablet weight } \mathrm{x} \text { target drug content for whole tablets } \\
\text { measured whole tablet weight }\end{array}$ \\
\hline $\begin{array}{l}\text { Percent of weight-adjusted drug } \\
\text { content }\end{array}$ & $\begin{array}{l}\text { Measured half-tablet drug content as a percent of weight-adjusted target drug content. } \\
\text { measured drug content for half-tablet x } 100 \\
\text { weight-adjusted target drug content }\end{array}$ \\
\hline Percent of target drug content & $\begin{array}{l}\text { For each tablet or half-tablet, expresses measured drug content as a percentage of target drug content. } \\
\text { Whole tablets: } \frac{\text { Measured drug content for whole tablet }}{\text { Target drug content for whole tablets }} 100 \\
\text { Half-tablets: } \frac{\text { Measured drug content for half-tablet x }}{\text { Target drug content for half-tablets }} \\
\quad\end{array}$ \\
\hline Percent of target weight & $\begin{array}{l}\text { For each tablet or half-tablet, expresses measured weight as a percentage of target weight. } \\
\text { Whole tablets: } \frac{\text { Measured weight for whole tablet }}{\text { Target weight for whole tablets }} 100 \\
\text { Half-tablets: } \frac{\text { Measured weight for half-tablet }}{\text { Target weight for half-tablets }} 100\end{array}$ \\
\hline Mean percent weight loss & $\begin{array}{l}\text { The amount of drug loss caused by the splitting process. } \\
\text { weight of whole tablet }- \text { weight of half-tablet \#1 - weight of half-tablet \#2 } \times 100 \\
\text { weight of whole tablet }\end{array}$ \\
\hline $\begin{array}{l}\text { Proxy USP specification for drug } \\
\text { content }\end{array}$ & $\begin{array}{l}\text { Measured drug content of whole or half-tablets within 95\%-105\% of target drug content for half-tablets for } \\
\text { warfarin sodium and within } 90 \%-110 \% \text { of target drug content for half-tablets for simvastatin, metoprolol succinate, } \\
\text { metoprolol tartrate, citalopram, and lisinopril. }\end{array}$ \\
\hline Proxy USP specification for weight & $\begin{array}{l}\text { Measured weight of whole or half-tablets within } 95 \%-105 \% \text { of target weight for half-tablets for warfarin sodium } \\
\text { and within } 90 \%-110 \% \text { of target weight for half-tablets for simvastatin, metoprolol succinate, metoprolol tartrate, } \\
\text { citalopram, and lisinopril. }\end{array}$ \\
\hline Proxy USP specification for \%RSD & \%RSD for whole or half-tablets less than $6 \%$. \\
\hline
\end{tabular}

fall within 95\%-105\% for warfarin sodium and 90\%-110\% for the other 5 drugs studied (proxy USP specification for drug content) according to the individual USP drug monographs. Because no USP criteria for drug content uniformity of half-tablets have yet been established, this study applied the proxy USP specification for whole tablets to half-tablets. It should be noted that the proxy USP specification ranges chosen for this study are the more stringent of ranges described within the individual USP monographs.
The tighter range is typically applied to samples of 20 or greater. However, individual tablets are typically subjected to a specification range of $85 \%-115 \%$.

Relative standard deviation expressed as a percentage (\%RSD), which is a ratio of the standard deviation to the mean of the variable being analyzed, was calculated for whole tablets (drug content and weight) and for half-tablets (drug content, weightadjusted drug content, and weight). The \%RSD is widely used to 
TABLE 3 Whole- and Half-Tablet Drug Content

\begin{tabular}{|c|c|c|c|c|c|c|}
\hline Drug & & $\begin{array}{c}\text { Target Drug } \\
\text { Content }(\mathrm{mg})^{\mathrm{a}}\end{array}$ & $\begin{array}{c}\text { Measured Drug } \\
\text { Content } \\
\text { Mean }(\mathrm{mg})^{\mathrm{b}}\end{array}$ & $\%$ RSD & $\begin{array}{c}\text { Percent of Target } \\
\text { Drug Content - } \\
\text { Range }^{c}\end{array}$ & $\begin{array}{c}\text { Outside of } \\
\text { Proxy USP } \\
\text { Specification }\end{array}$ \\
\hline Warfarin sodium & Whole $(n=15)$ & --- & 5.12 & 1.81 & $97.39-102.66$ & 0 \\
\hline Simvastatin & Whole $(n=15)$ & --- & 77.61 & 3.27 & $95.74-107.15$ & 0 \\
\hline Metoprolol succinate & Whole $(n=15)$ & --- & 196.07 & 1.63 & $97.39-102.71$ & 0 \\
\hline Metoprolol tartrate & Whole $(n=15)$ & --- & 25.29 & 2.82 & $94.68-106.81$ & 0 \\
\hline Citalopram & Whole $(n=15)$ & --- & 38.25 & 3.12 & $96.14-107.80$ & 0 \\
\hline Lisinopril & Whole $(n=15)$ & $-\cdots$ & 40.91 & 2.05 & $95.46-104.35$ & 0 \\
\hline Warfarin sodium & Half $(\mathrm{n}=30)$ & 2.56 & 2.57 & 5.05 & $90.01-109.40$ & $11(36.7 \%)$ \\
\hline Simvastatin & Half $(n=30)$ & 38.80 & 40.06 & 4.29 & $95.21-111.35$ & $3(10.0 \%)$ \\
\hline Metoprolol succinate & Half $(n=30)$ & 98.04 & 98.26 & 8.98 & $82.77-115.92$ & $10(33.3 \%)$ \\
\hline Metoprolol tartrate & Half $(\mathrm{n}=30)$ & 12.64 & 13.14 & 4.73 & $94.83-112.37$ & $4(13.3 \%)$ \\
\hline Citalopram & Half $(n=30)$ & 19.13 & 19.93 & 4.50 & $96.50-111.93$ & $5(16.7 \%)$ \\
\hline Lisinopril & Half $(\mathrm{n}=30)$ & 20.46 & 21.80 & 10.41 & $81.15-125.72$ & $10(33.3 \%)$ \\
\hline Warfarin sodium & Half wt adj $(n=30)$ & --- & 2.55 & 4.64 & $95.80-107.15$ & $3(10.0 \%)$ \\
\hline Simvastatin & Half wt adj $(n=30)$ & --- & 38.77 & 3.45 & $98.95-107.79$ & 0 \\
\hline Metoprolol succinate & Half wt adj $(n=30)$ & $-\cdots$ & 97.87 & 7.67 & $93.81-104.08$ & 0 \\
\hline Metoprolol tartrate & Half wt adj $(n=30)$ & --- & 12.57 & 5.26 & $101.00-108.08$ & 0 \\
\hline Citalopram & Half wt adj $(n=30)$ & $-\cdots$ & 19.08 & 3.18 & $97.89-110.75$ & $1(3.33 \%)$ \\
\hline Lisinopril & Half wt adj $(n=30)$ & --- & 22.00 & 8.07 & $94.23-112.08$ & $1(3.33 \%)$ \\
\hline
\end{tabular}

aTarget drug content for whole tablets is equal to the measured drug content mean per tablet for the sample. Target drug content for half-tablets is one-half of the measured drug content mean.

${ }^{b}$ Mean drug content values per whole tablet or half-tablet as determined by HPLC.

cA range (smallest to largest) representing measured drug content for whole or half-tablets expressed as a percent of target drug content.

${ }^{d}$ Number of whole or half-tablets with measured drug content not within 95\%-105\% of target drug content for warfarin sodium or 90\%-110\% of target drug content for simvastatin, metoprolol succinate, metoprolol tartrate, citalopram, and lisinopril.

HPLC = high performance liquid chromatography; $m g=$ milligram; \%RSD = relative standard deviation expressed as a percentage; USP=United States Pharmacopeia; wt adj= weight-adjusted.

assess the repeatability and precision of the assays used to analyze drug content. The \%RSD for drug content for all drugs studied was calculated using the following equation: (standard deviation for measured drug content / measured drug content mean) x 100 . The \%RSD for weight for all drugs studied was calculated using the following equation: (standard deviation for measured weight / measured weight mean) x 100. Individual medication lots for whole tablets are targeted to have a \%RSD less than 6\% (proxy USP specification for \%RSD). ${ }^{5}$

The percentage by which weight-adjusted drug content differed from target drug content was calculated using the following equation: (measured drug content for half-tablet / weight-adjusted target drug content for half-tablet) x 100 .

\section{Results}

\section{Drug Content}

For all whole tablets studied, measured drug content expressed as a percent of target drug content was found to fall within the proxy USP specification percentage range (Table 3). All whole tablets also met the proxy USP specification for \%RSD. The measured drug content expressed as a percent of target drug content for half-tablets fell outside of the proxy USP specification for drug content for at least 3 half-tablets of each drug studied. A total of 43 of 180 half-tablets (23.9\%) fell outside of the proxy USP specification for drug content; warfarin sodium (11 of 30 half-tablets, $36.7 \%$ ), simvastatin (3 of 30 half-tablets, 10.0\%) metoprolol succinate (10 of 30 half-tablets, 33.3\%), metoprolol tartrate (4 of 30 half-tablets, $13.3 \%$ ), citalopram (5 of 30 half-tablets, $16.7 \%$ ), and lisinopril (10 of 30 half-tablets, 33.3\%). The measured drug content variations expressed as a percent of target drug content for half-tablets were, from smallest to the largest, warfarin sodium (90.01-109.40\%), simvastatin (95.21\%-111.35\%), metoprolol succinate (82.77\%-115.92\%), metoprolol tartrate (94.83\%-112.37\%), citalopram (96.50-111.93\%), and lisinopril (81.15\%-125.72\%). Metoprolol succinate and lisinopril were the only agents analyzed that fell outside of the proxy USP specification for \%RSD, with \%RSD values of $8.98 \%$ and $10.41 \%$, respectively.

Weight-adjusted drug content expressed as a percent of target drug content for half-tablets fell outside of the proxy USP specification for drug content for at least 1 half-tablet of 3 drugs-warfarin sodium, citalopram, and lisinopril (Table 3). A total of 5 of 180 half-tablets (2.78\%) fell outside of the proxy 
TABLE 4 Whole- and Half-Tablet Weight

\begin{tabular}{|c|c|c|c|c|c|c|c|}
\hline Drug & & $\begin{array}{c}\text { Target Weight } \\
(\mathrm{mg})^{\mathrm{a}}\end{array}$ & $\begin{array}{c}\text { Measured } \\
\text { Weight Mean } \\
(\mathrm{mg})^{\mathrm{b}}\end{array}$ & $\%$ RSD & $\begin{array}{c}\text { Mean Percent } \\
\text { Weight } \\
\text { Loss (SD)c }\end{array}$ & $\begin{array}{c}\text { Percent of Target } \\
\text { Weight - Range }\end{array}$ & $\begin{array}{c}\text { Outside of } \\
\text { Proxy USP } \\
\text { Specification }\end{array}$ \\
\hline Warfarin sodium & Whole $(n=15)$ & --- & 219.99 & 1.03 & --- & $97.87-101.64$ & 0 \\
\hline Simvastatin & Whole $(n=15)$ & --- & 814.59 & 0.45 & --- & $99.17-100.76$ & 0 \\
\hline Metoprolol succinate & Whole $(n=15)$ & --- & 700.69 & 0.75 & --- & $98.82-101.34$ & 0 \\
\hline Metoprolol tartrate & Whole $(n=15)$ & --- & 153.85 & 0.82 & --- & $98.73-102.27$ & 0 \\
\hline Citalopram & Whole $(n=15)$ & --- & 268.05 & 0.89 & --- & $98.00-101.44$ & 0 \\
\hline Lisinopril & Whole $(n=15)$ & --- & 224.33 & 0.99 & --- & $98.65-102.21$ & 0 \\
\hline Warfarin sodium & Half $(n=30)$ & 110.00 & 109.36 & 4.73 & $0.50(0.46)$ & $90.69-108.88$ & $10(33.3 \%)$ \\
\hline Simvastatin & Half $(\mathrm{n}=30)$ & 407.30 & 404.09 & 3.51 & $0.08(0.04)$ & $93.32-105.97$ & 0 \\
\hline Metoprolol succinate & Half $(\mathrm{n}=30)$ & 350.35 & 349.62 & 7.70 & $0.17(0.47)$ & $85.71-112.97$ & $6(20.0 \%)$ \\
\hline Metoprolol tartrate & Half $(n=30)$ & 76.92 & 76.91 & 5.38 & $0.57(0.31)$ & $91.83-109.05$ & 0 \\
\hline Citalopram & Half $(\mathrm{n}=30)$ & 134.03 & 132.84 & 3.37 & $0.24(0.16)$ & $92.24-107.38$ & 0 \\
\hline Lisinopril & Half $(n=30)$ & 112.17 & 110.30 & 8.13 & $1.25(1.14)$ & $82.16-113.27$ & $7(23.3 \%)$ \\
\hline \multicolumn{8}{|c|}{ 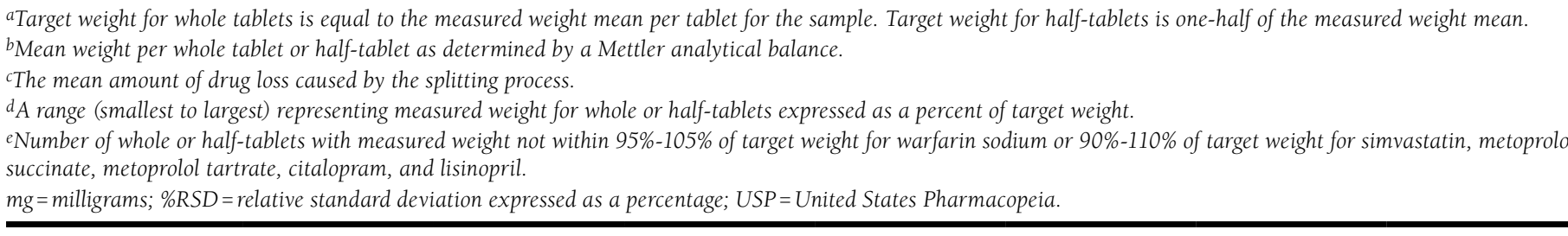 } \\
\hline
\end{tabular}

USP specification for drug content after weight adjustment; these included warfarin sodium ( 3 of 30 half-tablets, 10\%), citalopram (1 of 30 half-tablets, 3.33\%), and lisinopril (1 of 30 half-tablets, 3.33\%). Metoprolol succinate and lisinopril were the only agents analyzed that fell outside of the proxy USP specification for \%RSD after weight adjustment, with \%RSD values of $7.67 \%$ and $8.07 \%$, respectively.

\section{Weight}

For all whole tablets studied, measured weight expressed as a percent of target weight was found to fall within the proxy USP specification for weight (Table 4). All whole tablets also met the proxy USP specification for \%RSD. Measured weight expressed as a percent of target weight for half-tablets fell outside of the proxy USP specification for weight for at least 6 half-tablets of warfarin sodium, metoprolol succinate, and lisinopril. A total of 23 of 180 half-tablets (12.8\%) fell outside of the proxy USP specification for weight; these included warfarin sodium (10 of 30 half-tablets, $33.3 \%$ ), metoprolol succinate (6 of 30 half-tablets, 20.0\%), and lisinopril ( 7 of 30 half-tablets, 23.3\%). Metoprolol succinate and lisinopril were the only agents analyzed that fell outside of the proxy USP specification for \%RSD, with \%RSD values of $7.70 \%$ and $8.13 \%$, respectively.

Mean percent weight loss, after splitting, was less than $1 \%$ for all drugs with the exception of lisinopril: warfarin sodium $(0.50 \%)$, simvastatin $(0.08 \%)$, metoprolol succinate $(0.17 \%)$, metoprolol tartrate $(0.57 \%)$, citalopram $(0.24 \%)$, and lisinopril (1.25\%; Table 4).

\section{Scored Versus Nonscored Tablets}

A total of 20 of 90 (22.2\%) half-tablets of scored medications, and a total of 23 of 90 (25.6\%) half-tablets of nonscored medications fell outside of the proxy USP specification for drug content (Table 5). The numbers of half-tablets for scored (nonscored) drugs falling outside of range for drug content were 36 (44) for 95\%-105\%, 9 (23) for 90\%-110\%, 0 (10) for $85 \%-115 \%$, and 0 (1) for $75 \%-125 \%$.

A total of 10 of 90 (11.1\%) half-tablets of scored medications, and a total of 13 of 90 (14.4\%) half-tablets of nonscored medications fell outside of the proxy USP specification for weight (Table 6). The numbers of half-tablets for scored (nonscored) drugs falling outside of range for weight were 28 (38) for 95\%-105\%, 0 (14) for $90 \%-110 \%, 0$ (3) for $85 \%-115 \%$, and 0 (0) for $75 \%-125 \%$.

\section{Discussion}

When measured half-tablet drug content was compared against target drug content (one-half of the sample mean drug content) for each of 6 study medications, 43 of 180 half-tablets (23.9\%) fell outside of a proxy USP specification percentage range. Warfarin sodium had the highest number of half-tablets falling out of its proxy specification range, most likely due to its narrower specification window of 95\%-105\%. Metoprolol succinate and lisinopril were found to have a relatively large number of half-tablets with drug content falling outside of the range of $90 \%-110 \%$. Variation in half-tablet drug content was greatest with lisinopril, which had tablet halves ranging from $81.15 \%$ to $125.72 \%$ of the target drug 


\section{TABLE 5 Comparison of Scored and Nonscored Half-Tablets: Drug Content}

\begin{tabular}{|c|c|c|c|c|c|c|c|}
\hline Tablet type & $\mathrm{n}$ & $\begin{array}{c}\text { Percent of Target } \\
\text { Drug Content - } \\
\text { Range }^{\mathrm{a}}\end{array}$ & $\begin{array}{c}\text { Outside of } \\
\text { Proxy USP } \\
\text { Specification }^{b}\end{array}$ & $\begin{array}{l}\text { Out of Range } \\
(95 \%-105 \%)^{c}\end{array}$ & $\begin{array}{l}\text { Out of Range } \\
(90 \%-110 \%)^{c}\end{array}$ & $\begin{array}{l}\text { Out of Range } \\
(85 \%-115 \%)^{c}\end{array}$ & $\begin{array}{l}\text { Out of Range } \\
(75 \%-125 \%)^{c}\end{array}$ \\
\hline Scored ${ }^{\mathrm{d}}$ & 90 & $89.85-112.37$ & $20(22.2 \%)$ & $36(40.0 \%)$ & $9(10.0 \%)$ & 0 & 0 \\
\hline Nonscored $^{\mathrm{e}}$ & 90 & $81.15-125.72$ & $23(25.6 \%)$ & $44(48.9 \%)$ & $23(25.9 \%)$ & $10(11.1 \%)$ & $1(1.1 \%)$ \\
\hline \multicolumn{8}{|c|}{$\begin{array}{l}{ }^{a} \text { A range (smallest to largest) representing measured drug content for whole or half-tablets expressed as a percent of target drug content. } \\
{ }^{2} \text { Number of half-tablets with measured drug content not within 95\%-105\% of target drug content for half-tablets for warfarin sodium or } 90 \%-110 \% \text { of target drug content } \\
\text { for half-tablets for simvastatin, metoprolol succinate, metoprolol tartrate, citalopram, and lisinopril. } \\
{ }^{D} \text { Determined by HPLC. The number (\%) of half-tablets that fell outside of the range listed for drug content expressed as a percentage of target half-tablet drug content. } \\
{ }^{d} \text { Warfarin sodium, metoprolol tartrate, and citalopram tablets were scored. } \\
\text { eSimvastatin, metoprolol succinate, and lisinopril tablets were not scored. } \\
\text { HPLC= high performance liquid chromatography; USP = United States Pharmacopeia. }\end{array}$} \\
\hline
\end{tabular}

\section{TABLE 6 Comparison of Scored and Nonscored Half-Tablets: Weight}

\begin{tabular}{|c|c|c|c|c|c|c|c|}
\hline Tablet type & $\mathbf{n}$ & $\begin{array}{l}\text { Percent of Mean } \\
\text { Weight - Range }^{\text {a }}\end{array}$ & $\begin{array}{l}\text { Outside of proxy } \\
\text { USP Specification }\end{array}$ & $\begin{array}{l}\text { Out of Range } \\
(95 \%-105 \%)^{c}\end{array}$ & $\begin{array}{l}\text { Out of Range } \\
(90 \%-110 \%) c\end{array}$ & $\begin{array}{l}\text { Out of Range } \\
(85 \%-115 \%) c\end{array}$ & $\begin{array}{l}\text { Out of Range } \\
(75 \%-125 \%) c\end{array}$ \\
\hline Scored $^{\mathrm{d}}$ & 90 & $90.69-109.05$ & $10(11.1 \%)$ & $28(31.1 \%)$ & 0 & 0 & 0 \\
\hline Nonscorede & 90 & $82.16-113.27$ & $13(14.4 \%)$ & $38(42.2 \%)$ & $14(15.6 \%)$ & $3(3.3 \%)$ & 0 \\
\hline
\end{tabular}

a A range (smallest to largest) representing measured weight for whole or half-tablets expressed as a percent of target weight.

${ }^{b}$ Number (\%) of half-tablets with measured weight not within the 95\%-105\% specification range for warfarin sodium or $90 \%-110 \%$ for the other 5 drugs.

'Determined by Mettler analytical balance. The number (\%) of half-tablets that fell outside of the range listed for drug weight expressed as a percentage of target half-tablet drug weight.

${ }^{d}$ Warfarin sodium, metoprolol tartrate, and citalopram tablets were scored.

eSimvastatin, metoprolol succinate, and lisinopril tablets were not scored.

USP = United States Pharmacopeia.

content for half-tablets. Thus, when tablet splitting is performed for this lot of lisinopril, patients may receive daily doses that vary by as much as $45 \%$.

Several potential reasons could explain the observed variation in lisinopril half-tablet drug content. Inaccuracy during the tablet splitting process may have produced variability between tablet halves due to unequal half-tablet size. This argument is supported by the weight-adjusted data: Only a single lisinopril half-tablet fell outside of the range of 90\%-110\% when half-tablet drug content was adjusted for weight as compared with 10 halftablets when the data were not adjusted for weight. The results for lisinopril may also have been affected by weight loss due to the powdering and fragmenting that occurred during tablet splitting. Although lisinopril half-tablets were shown to have a mean percent weight loss of $1.25 \%$, the majority of lisinopril half-tablets did not fall outside the proxy USP specification for drug content until the weight loss was greater than $1.72 \%$.

Both metoprolol succinate and metoprolol tartrate may also have been affected by the inability of the tablet splitting device to accurately split medications into 2 equal halves. Additionally, for metoprolol succinate, a greater percent of drug content variation may be attributed to tablet formulation, specifically regarding the sustained release mechanism. This drug is found within nondis- solving pellets intended to provide a slow release of the drug. Without the ability to visualize the inside of individual drug pellets, complete dissolution could not be easily determined.

Metoprolol succinate and lisinopril were shown to have \%RSD values greater than $6 \%$ with regard to drug content and weight. This finding indicates that tablets of these medications are not easily split into equal halves when using a tablet-splitting device. Lisinopril had the greatest degree of drug content variability, with a \%RSD of greater than $10 \%$, perhaps in part because lisinopril had the greatest amount of weight loss from splitting. The high level of variability for metoprolol succinate may be due to the extended release drug delivery system.

Following the splitting process, half-tablet weight measurements revealed unequal splitting; this finding is likely a result of tablet powdering and limitations of the tablet splitter, person, and device. When half-tablet drug content was adjusted for weight, a large reduction in drug content variation was found. Thus, halftablet weight appears to be directly correlated with drug content. When compared with the target drug content of a perfectly split tablet half, 43 of 180 half-tablets (23.9\%), but only 5 of 180 weight-adjusted half-tablets (2.8\%), fell outside of proxy USP specification for drug content. Warfarin sodium accounted for the majority of weight-adjusted half-tablets falling outside of proxy 
USP specification for drug content ( 3 of the 5 half-tablets). It was also observed that the \%RSD for weight-adjusted drug content for all medications was reduced in comparison with non-weightadjusted drug content. These results would appear to indicate that the drug is uniformly dispersed within single whole tablets.

The data suggest greater variability in half-tablet drug content and weight for nonscored medications than for scored medications. Although nonscored and scored tablets produced roughly an equivalent number of half-tablets falling outside of proxy USP specification for drug content and weight, it was found that greater variability existed with the nonscored drug tablets. More nonscored drug half-tablets were found to have drug content and weight within the ranges of $85 \%-115 \%$ and $75 \%-125 \%$. This finding suggests that when a tablet-splitting device is used, dose administration may be more accurate and consistent for scored than nonscored medications; however, a larger sample of scored and nonscored tablets is needed to determine if there is a significant difference between scored and nonscored tablets.

The pharmacokinetics and the mechanisms by which these medications act would appear to dictate that half-tablet regimens may or may not have a clinical impact on long-term patient outcomes. Metoprolol succinate, lisinopril, and citalopram are agents with long durations of action, in which minor dose variation should have no significant impact on steady state plasma concentrations. Additionally, citalopram efficacy is highly subjective; thus, daily efficacy measurements can be variable regardless of small dose variation. Statins, including simvastatin, are agents designed to prevent downstream medical problems such as acute coronary syndromes and stroke; thus, small changes in daily dose should have no significant impact on long-term clinical end points. Lastly, antihypertensives, including angiotensin-converting enzyme inhibitors and beta blockers, are used to prevent medical problems associated with an elevated blood pressure over an extended period of time, thus, daily fluctuations in dose would be expected to affect blood pressure measurements and side effects and have no effect on long-term clinical end points.

In contrast, caution should be taken when splitting warfarin sodium due to the potential for significant adverse events with minimal change in daily dose. However, daily variation of international normalized ratio (INR) values, the parameter used to monitor warfarin sodium efficacy, can result from food interactions, drug interactions, and variations in daily dose. For this reason, it cannot be stated that the minor differences in warfarin sodium half-tablet drug content will predict clinical outcomes.

\section{Comparison With Previous Research and Clinical Significance}

In order to determine true clinical significance of tablet splitting, studies looking at clinical outcomes must be examined. Four studies known to these authors have evaluated the clinical impact of half-tablet regimens: 3 assessing statins and 1 assessing lisinopril. ${ }^{10-13}$ All 4 studies have shown that the dose inaccuracy experienced from splitting tablets does not significantly affect primary outcomes. The study by Duncan et al. (2002) performed at a VA medical center examined triglycerides, low-density lipoprotein cholesterol (LDL-C), high-density lipoprotein cholesterol (HDL-C), and total cholesterol values for 109 patients enrolled in a statin (atorvastatin and simvastatin) tablet splitting program. ${ }^{10}$ The study concluded that there was a significant decrease in total cholesterol (187.6 mg per deciliter [dL] to $179.7 \mathrm{mg}$ per $\mathrm{dL} ; P=0.005)$ and LDL-C (111.6 mg per dL to $105.1 \mathrm{mg}$ per $\mathrm{dL}$; $P=0.004$ ) after at least 6 weeks following the initiation of the split tablet program. Duncan et al. concluded that there was no clinically significant difference comparing the time periods before and after the initiation of the tablet-splitting program.

A similar study performed at a different VA medical center assessed clinical endpoints before and after the initiation of a tablet-splitting program for 2,019 patients. ${ }^{11}$ This study by Gee et al. (2002) also found no clinically significant changes in serum lipid levels before and after implementation of the tablet-splitting program. A more recent retrospective chart review was performed across 6 VA medical centers, comparing 3,196 patients assigned to a split-tablet regimen with a whole-tablet regimen of varying simvastatin doses..$^{12}$ Similar to the other previously mentioned studies, no statistically significant difference in LDL-C was found between patients in the split-tablet group and in the whole-tablet comparison group $(P=0.304)$. A randomized crossover study performed at another VA medical center found no statistically significant differences in systolic or diastolic blood pressure for patients treated with whole- and half-tablet regimens for lisinopril. ${ }^{13}$ No studies to date have been performed that assess the clinical impact of half-tablet regimens for citalopram, metoprolol tartrate, metoprolol succinate, or warfarin sodium; thus, no conclusions about the clinical impact of half-tablet regimens for these agents can be made.

\section{Limitations}

First, the USP has not created a method for assessing half-tablet drug content uniformity; thus, previous studies assessing halftablet drug content uniformity have used adapted USP methods for assessing weight variability as a means of estimating drug content uniformity. Second, all of the medications in this study are now available generically, and there is little financial value in splitting these particular drugs today. Third, the medications chosen for analysis were determined by prevalence of tablet splitting within a single health care network. The medications studied may not be representative of the most commonly split medications, and the purpose of the present research is not to suggest which drug classes may or may not be split. For these reasons, health care practitioners may not extrapolate the findings of this study to medications not studied. Fourth, the only tablet-splitting technique studied was the use of a tablet-splitting device. Splitting by hand or with sharp instruments including knives and razor blades are also commonly used techniques 
in the outpatient setting. With greater precision and accuracy, tablet-splitting devices generally provide greater consistency in half-tablet doses. Thus, tablets split using other techniques may lead to greater variability than that observed in this study. Fifth, a single pharmacy student performed all tablet splitting and weight measurements in an intentional effort to eliminate variability that might be introduced by multiple testers. However, this tester's technique may not be representative of tablet-splitting when performed by patients in the general population. In particular, certain patient populations may have increased difficulty splitting tablets, such as the elderly and patients with arthritis, movement disorders, or poor cognitive function. Lastly, this research does not permit clinical conclusions since no clinical end points were assessed.

\section{Conclusion}

Dose variation, measured as the difference between actual halftablet drug content and sample mean drug content, exceeded a proxy USP specification for more than one-third of sampled half-tablets of warfarin sodium, metoprolol succinate, and lisinopril. The percentages of half-tablets exceeding a proxy USP specification for drug content were roughly equal for scored and nonscored tablets; however, dose variation appeared to be greater with nonscored tablets. Fewer half-tablets in a weight-adjusted analysis than in an analysis that was not weight-adjusted fell outside of the proxy USP specification for drug content. Thus, drug content variation in half-tablets appears to be attributable primarily to weight variation occurring when tablets powder or fragment during the splitting process. Therefore, equal daily doses will be determined by the ability of patients to split tablets perfectly in half.

\section{DISCLOSURES}

The authors reported no external funding for this research and no financial or other conflicts of interest related to the subject of this manuscript.

Hill was primarily responsible for the study concept and design, with assistance from Karlage and Myrdal. The data were collected primarily by Hill and Varker, with assistance from Karlage. Hill and Myrdal interpreted the data, with assistance of the other 2 authors. Hill and Varker wrote the manuscript, and Varker was primarily responsible for revision of the manuscript, with assistance from the other 3 authors.

\section{REFERENCES}

1. Cohen CI, Cohen SI. Potential cost savings from pill splitting of newer psychotropic medications. Psychiatr Serv. 2000;51(4):527-29.

2. Cohen CI, Cohen SI. Potential savings from splitting newer antidepressant medications. CNS Drugs. 2002;16(5):359-60.

3. Miller DP, Furberg CD, Small RH, et al. Controlling prescription drug expenditures: a report of success. Am J Manag Care. 2007;13(8):47380. Available at: http://www.ajmc.com/files/articlefiles/AJMC_07auf_ Miller473to480.pdf. Accessed February 5, 2009.

\section{Authors}

SHAYNAN W. HILL, PharmD, is Pharmacy Practice Resident, Department of Pharmacy, Long Beach Veterans Affairs Health Care System, Long Beach, California. (At the time this study was performed, Hill was a fourth-year pharmacy student, University of Arizona College of Pharmacy, Tucson, Arizona.) ANDREW S. VARKER, PharmD, is Pharmacy Practice Resident, Department of Pharmacy, Phoenix Veterans Affairs Health Care System, Phoenix, Arizona. (At the time this study was performed, Varker was a fourth-year pharmacy student at the University of Arizona College of Pharmacy, Tucson, Arizona.) KELLY KARLAGE, BS, is Chemist, and PAUL B. MYRDAL, PhD, is Associate Professor of Pharmaceutics, University of Arizona College of Pharmacy, Tucson, Arizona.

CORRESPONDENCE: Shaynan Hill, PharmD, Pharmacy Practice Resident, Department of Pharmacy, Long Beach Veterans Affairs Hospital, 5901 E. 7th St. (119), Long Beach, CA 90822. Tel.: 520.990.0847; E-mail: shaynan_wynne@yahoo.com

4. Stafford RS, Radley DC. The potential of pill splitting to achieve cost savings. Am J Manag Care. 2002;8:706-12. Available at: http://www.ajmc.com/ files/articlefiles/AJMC2002augStafford706_712.pdf. Accessed February 5, 2009.

5. The Official Compendia of Standards, USP28/NF23. Rockville, MD: United States Pharmacopeia Convention, Inc. 2005 Official Monographs and Uniformity of Dosage Units.

6. Teng J, Song CK, Williams RL, Polli JE. Lack of medication dose uniformity in commonly split tablets. J Am Pharm Assoc (Wash). 2002;42(2):195-99.

7. Polli JE, Kim S, Martin BR. Weight uniformity of split tablets required by a Veterans Affairs policy. J Manag Care Pharm. 2003;9(5):401-07. Available at: http://www.amcp.org/data/jmcp/Research-401-407.pdf.

8. Cook TJ, Edwards S, Gyemah C, Shah M, Shah I, Fox T. Variability in tablet fragment weights when splitting unscored cyclobenzaprine $10 \mathrm{mg}$ tablets. J Am Pharm Assoc (2003). 2004;44(5):583-86.

9. Rosenberg JM, Nathan JP, Plakogiannis F. Weight variability of pharmacist-dispensed split tablets. J Am Pharm Assoc (Wash). 2002;42(2):200-05.

10. Duncan MC, Castle SS, Streetman DS. Effect of tablet splitting on serum cholesterol concentrations. Ann Pharmacother. 2002;36(2):205-09.

11. Gee M, Hasson NK, Hahn T, Ryono R. Effects of a tablet-splitting program in patients taking HMG-CoA reductase inhibitors: analysis of clinical effects, patient satisfaction, compliance, and cost avoidance. J Manag Care Pharm. 2002;8(6):453-58. Available at: http://www.amcp.org/data/jmcp/ Research-453-458.pdf.

12. Parra D, Beckey NP, Raval HS, et al., for the Veterans Integrated Service Network 8 Pharmacy Benefits Management Utilization Committee. Effect of splitting simvastatin tablets for control of low-density lipoprotein cholesterol. Am J Cardiol. 2005;95(12):1481-83.

13. Rindone JP. Evaluation of tablet-splitting in patients taking lisinopril for hypertension. J Clin Outcomes Manage. 2000;7(4):22-24. 